\title{
Regional Cerebral Blood Flow in Patients with Aneurysms: Estimation by Xenon 133 Inhalation
}

\author{
BRYCE WEIR, DEVIDAS MENON AND THOMAS OVERTON
}

SUMMARY: Seventy six regional cerebral blood flow ( $r C B F$ ) studies were conducted on 32 patients who had a total of 39 aneurysms. Twenty three of these patients were studied pre- and post-operatively. Normal values were obtained from a control group of 33 subjects, each of whom underwent one $C B F$ study. Flow was reduced following subarachnoid hemorrhage $(S A H)$; it increased significantly postoperatively. Lower flows were associated with poorer clinical grades. There was a

RÉSUMÉ: Nous avons effectué 76 études du flot sanguin cérébral régional ( $\mathrm{CCBF}$ ) chez 32 patients présentant un total de 39 anévrysmes. 23 de ces patients furent étudiés avant et après l'opération. Les valeurs normales proviennent de l'étude de 33 sujets contrôles ayant chacun subi une étude rCBF. Le flot était réduit après les hémorragies sous-arachnoidiennes (SAH); il augmenta de façon significative après l'opération. Les flots les plus bas sont associés aux scores cliniques les plus faibles. Il existe une plus grande variation dans la greater variation in regional distribution of flow immediately following SAH than in normals or in patients who had recovered from the acute phase. $r C B F$ studies correlated with $C T$ scans demonstrated that a progressive increase in ventricular size was accompanied by a progressive reduction in flow. In addition, intraventricular hemorrhage (IVH) was associated with a significant reduction in cerebral blood flow $(C B F)$. No significant correlation between $C B F$ and spasm was demonstrable.

distribution du flot régional immédiatement après unehémorragie sous-arachnoidienne que chez des normaux ou des patients en convalescence d'une phase aigue. Lorsque le $r C B F$ est comparé à la tomodensitométrie (CT Scan) on voit qu'une augmentation progressive de la grandeur des ventricules cérébraux s'accompagne d'une réduction progressive du flot. Enfin une hémorragie intraventriculaire s'accompagne d'une réduction importante du flot sanguin cérébral. Aucune corrélation ne fut montrée entre ce flot et la présence de spasmes.
From the Divisions of Neurosurgery and Biomedical Engineering, Faculty of Medicine, University of Alberta, Edmonton.

Reprint requests to: Dr. B. K. A. Weir, 520-8409112 Street, Edmonton, Alberta, T6G 1K6, Canada.

\section{INTRODUCTION}

The first specific study of cerebral blood flow (CBF) changes following subarachnoid hemorrhage (SAH) employed a diffusible indicator, Krypton 85, and was published in 1966 by Kagstrom et al. The authors demonstrated a moderate reduction in flow during the first few weeks after bleeding. This reduction amounted to about $20 \%$. One case was recorded in which a marked decrease in flow was accompanied by appropriate hemiplegia and dysphasia. In this case, angiography performed three days later revealed intense spasm.

Subsequent CBF studies have employed, in most cases, the radioisotope Xenon 133 administered via intracarotid injection, in association with angiography. This limited the general applicability of rCBF studied on patients with aneurysms, because subjecting patients to multiple angiographic studies was unjustifiable. This drawback was largely overcome with the development of a non-invasive inhalation method of rCBF determination. This method yields a number of parameters, most importantly the blood flow of the "fast" component of the brain (grey matter).

\section{METHOD}

The patients underwent neurological examination, clinical grading, computerized tomography, pre- and postoperative angiography, and rCBF studies. The flow studies were done using inhalation of Xenon-133. A oneminute inhalation, followed by ten minutes of clearance yielded flows; the analysis was performed by computer, using a program originally developed by Obrist et al (1975). Seven scintillation detectors measured flow in one hemisphere; the hemisphere ipsilateral 
to the aneurysms was studied, except in midline aneurysms when the right side was studied. Presence or absence of spasm was ascertained from the angiograms. CT scans were studied for evidence of IVH, SAH and intracerebral hemorrhage (ICH). The ventriculocranial ratio, which is the ratio of the width of the ventricles immediately behind the frontal horns between the caudate nuclei, to the width of the brain at the same level was measured from these scans.

\section{RESULTS}

All flow values are in $\mathrm{ml}$. of blood/100 $\mathrm{g}$ of tissue/minute, and are given as "flow \pm 1 standard deviation".

Thirty three rCBF studies were performed on the control group of 33 . Twenty two of these, all over 24 years of age (mean age: $32.9 \pm 7.2$ years), yielded a mean hemispherical flow of $67.1 \pm 17.2$. The remaining 11,24 years or under (mean age: $20.1 \pm 2.3$ years), had a mean flow of $81.1 \pm$ 15.3. In the older group, there is no significant reduction of flow with age.

Twenty three of the 32 patients with aneurysms had pre- and post-operative flow measurements. In all, 76 studies were carried out on all the patients (Figure 1). Sixty three of these were on patients who were clinically grade I or II. This group, with a mean age of 44.9 \pm 13.1 years, had a mean $\mathrm{CBF}$ of 59.5 \pm 13.2 ; this is $89 \%$ of the flow for the over-24 control group. The remaining

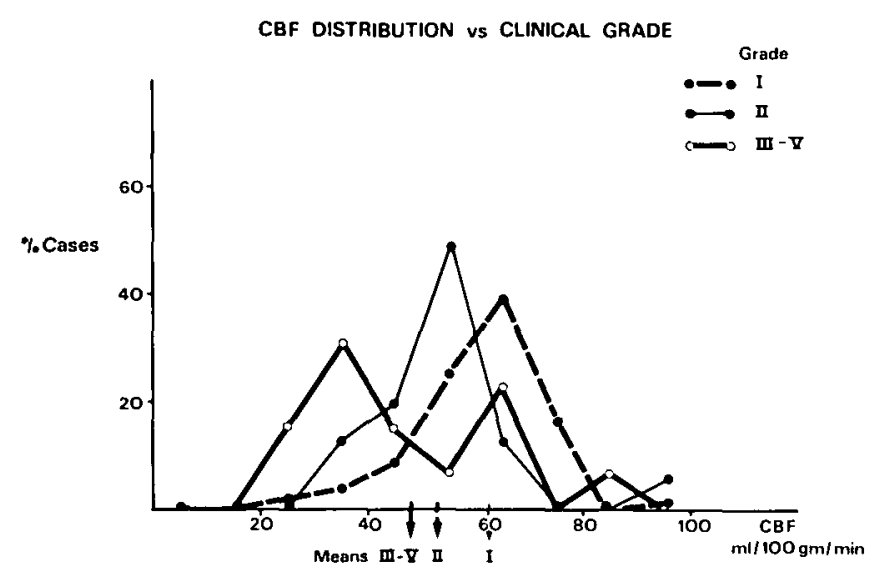

Figure 1: CBF distribution vs clinical grade

Statistically significant differences exist between Grade I flows and Grade II flows $(p<0.025)$ and between Grade I \& II flows and Grade III-V $(p<0.005)$

\begin{tabular}{|c|c|c|}
\hline \multicolumn{2}{|c|}{ CBF } \\
\hline & Present & Absent \\
\hline IVH & $43.7 \pm 11.0$ & $56.5 \pm 13.6$ \\
ICH & $51.0 \pm 28.8$ & $55.5 \pm 12.1$ \\
SAH & $55.3 \pm 18.0$ & $55.0 \pm 11.6$ \\
Any & $53.6 \pm 17.1$ & $56.4 \pm 10.7$ \\
\hline
\end{tabular}

Table 1: $\mathrm{CBF}$ in patients with and without hemorrhage visible in $\mathrm{CT}$ scans

IVH: intraventricular hemorrhage; ICH: intracerebral hemorrhage SAH: subarachnoid hemorrhage; Any: any of the above

CBF reduction in the presence of IVH is statistically significant $(p<0.1)$

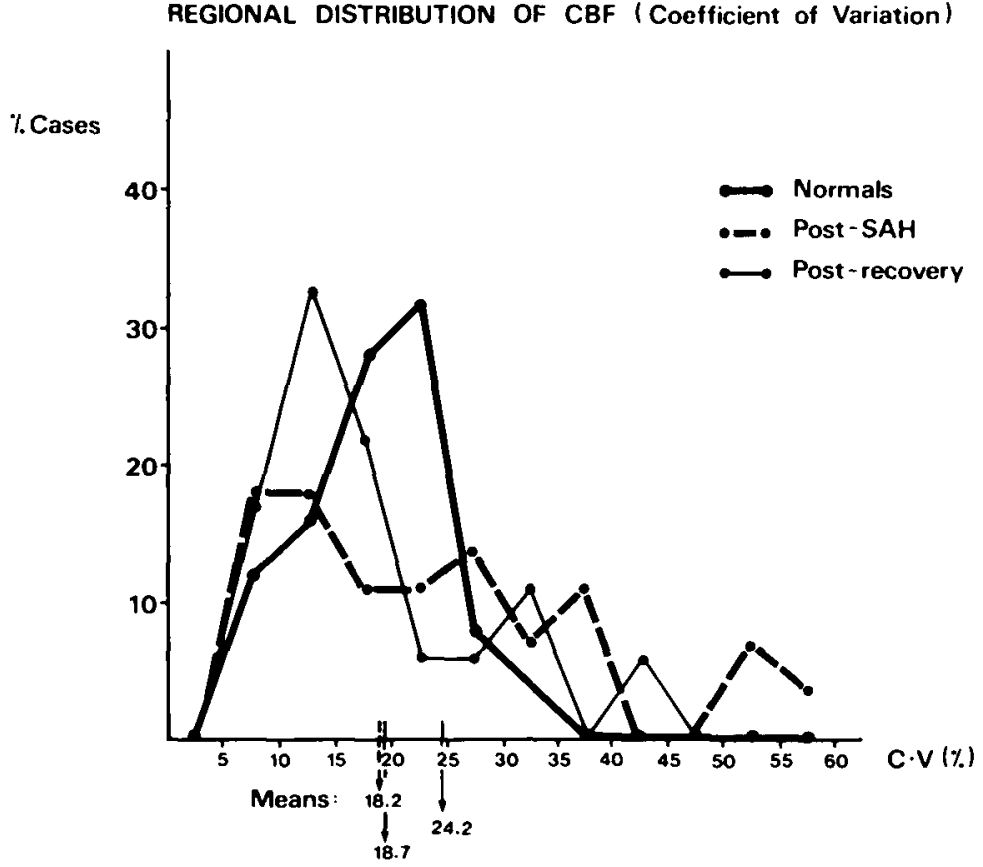

Figure 2: Regional distribution of CBF (Coefficient of variation) Mean Coefficient of Variation (CV):

Normals: $18.7 \%$

Post-SAH: $24.2 \%$

Post-recovery: $18.2 \%$
13 who were grade III, IV or V (mean age: $49.1 \pm 12.2$ years) had a mean flow of $47.5 \pm 18.4$, which is $71 \%$ of the "normal" value. Flow in patients with grade III, IV or V was $80 \%$ of that in grade I or II patients.

Thirty of the patients had SAH; the other 2 had severe ipsilateral headaches associated with giant aneurysms. The 2 patients who were not operable died. Of the 30 patients operated on, 2 died post-operatively for a $7 \%$ case mortality; the operative mortality was $6 \%$. The pre-operative mean CBF was 55.3 \pm 11.2 , which is significantly different $(p<0.005)$ from the post-operative mean of $66.2 \pm 8.3$.

The patients had a more abnormal regional distribution of flows within the hemisphere, in the sense of intrahemispherical variation, than the control group. This variation, as measured by the coefficient of variation (C V) had diminished three weeks following the $\mathrm{SAH} . \mathrm{C} \mathrm{V}$ in regional distribution of rCBF was significantly different, in the immediate post-SAH flows, from those 
CBF vs Time (from SAH)

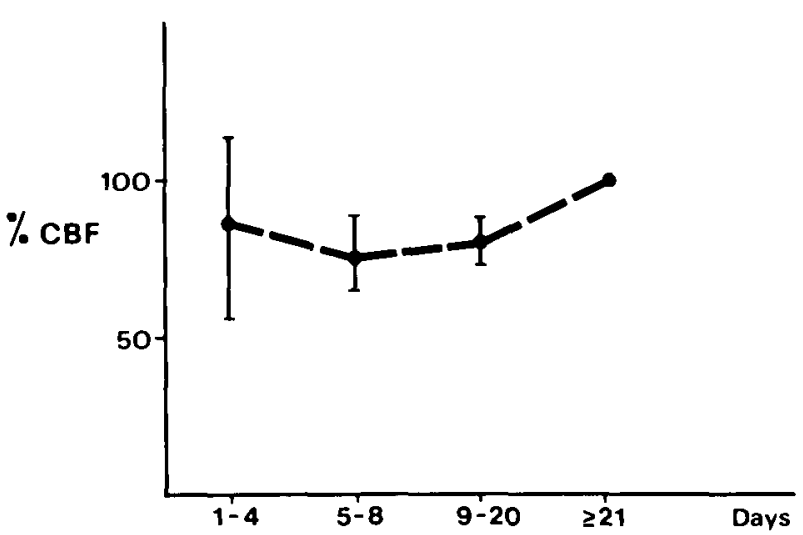

CBF vs VENTRICULOCRANIAL RATIO

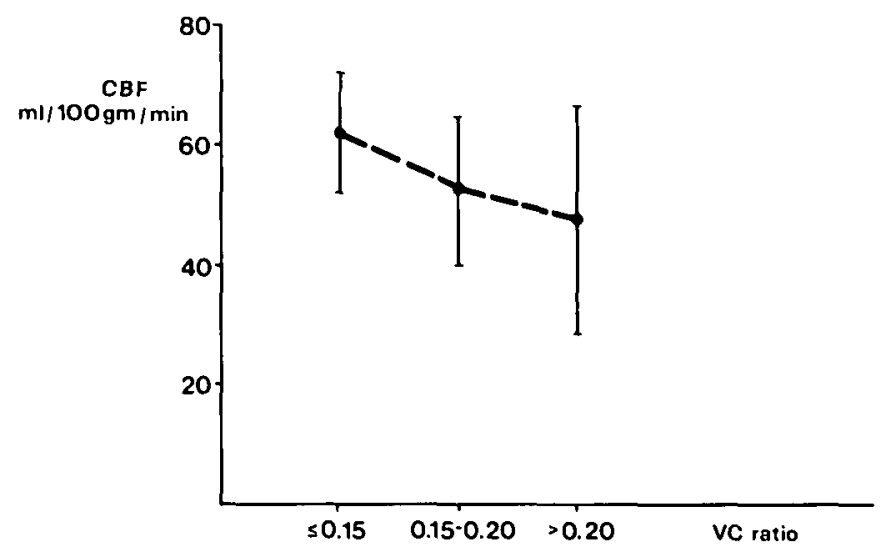

Figure 4: CBF vs Ventriculocranial Ratio

Figure 3: CBF vs Time (from SAH)

Flow values obtained 21 or more days after $\mathrm{SAH}$ are taken to be at the $100 \%$ level.

studied more than three weeks following hemorrhage and from the controls (Figure 2).

Although flows tended to diminish after about a week following $\mathrm{SAH}$, and to increase post-operatively (Figure 3 ), insufficient data was available to demonstrate any statistically significant differences between flows in the various time intervals selected.

CT scan - rCBF correlated studies showed that flow was significantly reduced when IVH was visible in the scan. However, visible SAH or ICH did not correlate with significantly altered flows (Table 1). Increased ventricular size as measured by the ventriculocranial ratio (VC ratio) was associated with poorer clinical grades. In addition, the mean flow tended to fall with increased ventricular size (Figure 4).

Of the 4 fatal cases, 2 were operated on. One of these had a high preoperative CBF of 88 which fell to 46 in the immediate post-operative period; this is a $47 \%$ decrease. Post-operative angiography revealed evolution of severe spasm. The second postoperative death had a pre-operative flow of 63 (grade I). The aneurysm was wrapped, but ruptured in the immediate post-surgical period, before further rCBF studies could be done. Of the 2 non-operated patients, one had a mean flow of 35 and was grade IV on her only study. The other patient had an initial flow of 40 (grade IV) which improved to 51 (grade II), but the patient suffered a subsequent hemorrhage and died before further flow studies could be conducted.

Serial rCBF measurements were made on one patient. On the tenth day following hemorrhage, he had a mean flow of 60 (grade II). On the fourteenth day post-SAH, there was clinical deterioration, with development of drowsiness and hemiplegia; the $\mathrm{CBF}$ had fallen to 24 , a $60 \%$ reduction. Five days later, the CBF was 32 and the patient had become more alert, though still densely hemiplegic. Ten days after the sudden deterioration, the patient was alert and hemiplegic, with a mean now of 43. Two days later, the patient underwent surgery and on the sixth post-operative day (thirty-second day post-SAH) the flow had continued to rise, with an improvement in the hemiplegia and maintenance of a normal level of consciousness; at this point, the mean CBF was 47.

Spasm was measured according to the definition of spasm index (SI) by Weir et al. (1978). Of 12 patients with lower flows (<55), 5 had SI $\leq 1.85$. Seventeen patients with higher flows $(>55)$ included 10 with SI $\leq 1.85$. There was clearly no correlation between spasm and CBF in this series. It should be noted, however, that the angiograms and flows were not done simultaneously and the correlation was done on studies less than 72 hours apart.

\section{DISCUSSION}

Eight of the more significant previous series (using Xenon 133 or Oxy- gen 15) conducted on patients with aneurysms are documented in Table 2. The studies using the intracarotid method were limited in the number of pre- and post-operative studies possible. It is a universal consensus that $\mathrm{CBF}$ is diminished following $\mathrm{SAH}$.

The correlation between a reduction of flow and angiographically observed spasm is more debatable. There appears to be no general consensus of opinion as to whether spasm does or does not modify CBF. Bergvall et al (1973), for example, concluded that the caliber of the large conducting arterial channels appears to be independent of CBF within wide limits; these authors also carried out quantitative measurement of vessel diameter. On the other hand, in the largest study to date by Pitts et al (1977), the authors concluded that angiographic cerebral vasospasm did significantly reduce CBF. The mean flows in the no-spasm and spasm groups were $40 \pm 1.5$ and $36 \pm 1.4$ respectively, a significant difference $(p<0.025)$. The difference became more marked, however, if those cases with no or only mild spasm were compared to those who had moderate or severe spasm; in this case, the mean flows became $40 \pm 1.1$ and $31 \pm 2.1(\mathrm{p}<0.005)$. Zingesser et al (1968) noted a poor correlation between $\mathrm{rCBF}$ and the presence or absence of spasm. In his 3 cases where bilateral measurements were made and where there was spasm and neurologic deficit, the reduction in flow was appropriate to the spasm and neurologic deficit. There are also marked excep- 
TABLE 2

CBF Studies Post-SAH: Methods of Testing and Conclusions

\begin{tabular}{|c|c|c|c|c|c|c|c|}
\hline Authors & Method & $\begin{array}{l}\text { No. of } \\
\text { Probes }\end{array}$ & $\begin{array}{l}\text { No. of } \\
\text { Cases }\end{array}$ & $\begin{array}{l}\text { No. of } \\
\text { Studies }\end{array}$ & $\begin{array}{c}\text { Cases } \\
\text { Pre- \& } \\
\text { Post-op }\end{array}$ & $\begin{array}{c}+ \text { CBF } \\
\text { Post- } \\
\text { SAH }\end{array}$ & $\begin{array}{l}\text { Corre- } \\
\text { lations: } \\
\text { Spasm } \\
\text { \& CBF }\end{array}$ \\
\hline $\begin{array}{l}\text { Zingesser et al } \\
\qquad(1968)\end{array}$ & ${ }^{133} \mathrm{Xe}(\mathrm{ICA})$ & 4 & 16 & 16 & 0 & $?$ & Poor \\
\hline James (1968) & ${ }^{133} \mathrm{Xe}(\mathrm{ICA})$ & 1 & 36 & 36 & 0 & Yes & Yes \\
\hline $\begin{array}{c}\text { Symon et al } \\
(1972)\end{array}$ & ${ }^{133} \mathrm{Xe}(\mathrm{ICA})$ & 16 & 16 & 17 & 1 & Yes & $?$ \\
\hline $\begin{array}{l}\text { Heilbrun et al } \\
(1972)\end{array}$ & ${ }^{133} \mathrm{Xe}(\mathrm{ICA})$ & 32 & 12 & 14 & 2 & Yes & Yes \\
\hline $\begin{array}{l}\text { Ferguson et al } \\
\quad(1972)\end{array}$ & $\begin{array}{c}{ }^{133} \mathrm{Xe}(\mathrm{ICA} \text { or } \\
\text { CCA })\end{array}$ & 4 & 15 & $?$ & $?$ & Yes & Yes \\
\hline $\begin{array}{l}\text { Bergvall et al } \\
(1973)\end{array}$ & $\begin{array}{c}{ }^{133} \mathrm{Xe} \text { (ICA or } \\
\text { CCA })\end{array}$ & 1 & 57 & 91 & 21 & Yes & No \\
\hline $\begin{array}{l}\text { Pitts et al } \\
(1977)\end{array}$ & $\begin{array}{c}{ }^{133} \mathrm{Xe}(\text { ICA or } \\
\text { Inhal) }\end{array}$ & $?$ & 111 & $?$ & $?$ & Yes & Yes \\
\hline $\begin{array}{c}\text { Grubb et al } \\
\quad(1977)\end{array}$ & ${ }^{15} 0(\mathrm{ICA})$ & $3-13$ & 30 & 45 & 9 & Yes & Yes \\
\hline Present Study & ${ }^{133} \mathrm{Xe}$ (Inhal) & 7 & 32 & 76 & 23 & Yes & No \\
\hline
\end{tabular}

tions. In one study (Ferguson et al, 1972) a patient with severe spasm had the highest flows in the series.

A reasonable conclusion would appear to be that correlation between a

reduced $\mathrm{CBF}$ and vasospasm is usually obvious when there is a marked reduction in flow and extreme vasospasm. It seems unlikely that significant differences in group data will emerge until

TABLE 3

CBF Post-SAH in Relation to Grade and Spasm

\begin{tabular}{|c|c|c|c|c|c|c|c|c|c|c|}
\hline Authors & $\begin{array}{l}\text { Analysis } \\
\text { Method }\end{array}$ & $\begin{array}{l}\text { CBF } \\
\text { (nor- } \\
\text { mals) }\end{array}$ & \multicolumn{2}{|c|}{$\begin{array}{c}\text { Good Grades } \\
\text { (I\&II) }\end{array}$} & \multicolumn{2}{|c|}{$\begin{array}{l}\text { Poor Grades } \\
\text { (III-V) }\end{array}$} & C & $\begin{array}{c}\mathrm{CBF} \\
\text { (No } \\
\text { spasm) }\end{array}$ & $\begin{array}{c}\text { CBF } \\
\text { (Spasm) }\end{array}$ & $\begin{array}{l}\underset{\text { with }}{\text { \% } C B F} \\
\text { Spasm }\end{array}$ \\
\hline James (1968) & $\begin{array}{l}\text { Bi-compart- } \\
\text { mental.-Fast } \\
\text { component }\end{array}$ & 70 & 65 & $93 \%$ & 49 & $70 \%$ & $25 \%$ & 62 & 47 & $24 \%$ \\
\hline $\begin{array}{c}\text { Symon et al } \\
(1972)\end{array}$ & $\begin{array}{l}\text { Weighted } \\
\text { Mean Flow }\end{array}$ & 50 & 39 & $78 \%$ & 28 & $56 \%$ & $28 \%$ & $?$ & $?$ & $?$ \\
\hline $\begin{array}{l}\text { Heilbrun et al } \\
(1972)\end{array}$ & $\mathrm{H} / \mathrm{A}$ & $?$ & 34 & $?$ & 29 & $?$ & $16 \%$ & $?$ & $?$ & $?$ \\
\hline $\begin{array}{l}\text { Ferguson et al } \\
(1972)\end{array}$ & $\mathrm{H} / \mathrm{A}$ & $?$ & 46 & $?$ & 32 & $?$ & $30 \%$ & 45 & 40 & $11 \%$ \\
\hline $\begin{array}{l}\text { Pitts et al } \\
(1977)\end{array}$ & $?$ & $?$ & 40 & $?$ & 36 & $?$ & $10 \%$ & 40 & 36 & $10 \%$ \\
\hline $\begin{array}{c}\text { Grubb et al } \\
(1977)\end{array}$ & ISI & 54 & $\begin{array}{l}42^{*} \\
36^{* *}\end{array}$ & $\begin{array}{l}78 \% \\
67 \%\end{array}$ & $\begin{array}{l}35^{*} \\
33^{* *}\end{array}$ & $\begin{array}{l}65 \% \\
61 \%\end{array}$ & $\begin{array}{l}17 \% \\
8 \%\end{array}$ & $\begin{array}{l}42 \text { (I\&II) } \\
35 \text { (III-V) }\end{array}$ & $\begin{array}{l}36(\text { I\&II) } \\
33(\text { III-V) }\end{array}$ & $\begin{array}{l}14 \% \\
6 \%\end{array}$ \\
\hline Present Study & $\begin{array}{l}\text { Bi-compart- } \\
\text { mental-Fast } \\
\text { component }\end{array}$ & 67 & 60 & $89 \%$ & 48 & $71 \%$ & $20 \%$ & $?$ & $?$ & $?$ \\
\hline
\end{tabular}

A: CBF post-SAH

$B$ : $\mathrm{CBF}$ as \% of normal

C: Additional \% reduction in CBF with reduction in consciousness.

All Flows are in $\mathrm{ml} / 100 \mathrm{~g} / \mathrm{min}$.

* No spasm

** Spasm larger number of cases are studied. Individual case studies indicate only that when there is severe spasm, there is likely to be an accompanying reduction in CBF and a poorer prognosis (Table 3).

In the study of Bergvall et al (1973) of patients with a favorable outcome, only $31 \%$ had flows less than 30 , whereas $73 \%$ of patients with bad results had sub-30 CBF. In addition, of the patients who did well and had multiple flow studies, only $8 \%$ showed a fall between successive studies. This compares to $14 \%$ in the patients who did poorly, and $100 \%$ in the patient that died. Pitts et al (1977) noted a mean flow of $39 \pm 1.5$ in patients with good outcome, whereas those who were dependent or died had a mean flow of $36 \pm 1.4$. Our study showed that $7 \%$ of fully recovered patients had reduction in $\mathrm{CBF}$ on repeat studies, as compared to the $50 \%$ of patients with a bad outcome.

It is not an unusual finding that focal neurological deficit did not correlate with a reduced $\mathrm{rCBF}$. The flow study presumably was not conducted at the time during which there was a focal depression of flow sufficient to produce infarction. In one series (Grubb et al, 1977), 47\% of patients with focal neurological deficits did not show an appropriate reduction in rCBF. Symon et al (1972), Zingesser et al (1968), and others have noted the occasional precise correlation between focal reduction of $\mathrm{CBF}$ and neurological deficit.

In this early phase of our experience with this investigative technique, we have not found it justifiable to perform arterial punctures in order to obtain $\mathrm{PaCO}_{2}$ values to correct the rCBF values. To be really useful clinically, flows will have to be measured serially on individual patients in which case this correction will, in most cases, be minimal. End-tidal $\mathrm{PCO}_{2}$ values might improve the reliability of our data without introducing any element of risk to the patient. In the work of Bergvall et al (1973), $\mathrm{PaCO}_{2}$ measurements were performed. They concluded that $\mathrm{PaCO}_{2}$ variations were generally small, resulting in insignificant correction of rCBF. James (1968) noted a degree of hypocapnia in patients who were most ill following SAH, but did not feel that 
this was the cause for depression of rCBF. This conclusion was reached because although the mean arterial $\mathrm{PaCO}_{2}$ in this group was not significantly different from that in patients who were less ill, the mean CBF values for the two groups differed significantly from each other. Obrist et al (1975) have been investigating the extent to which end-tidal $\mathrm{PCO}_{2}$ curves deviate from arterial $\mathrm{PaCO}_{2}$ curves in the aging population and assessing the influence on computed rCBF values. Their preliminary findings suggest that a substantial deviation is necessary before $\mathrm{rCBF}$ is affected. It seems, however, that in some cases arterial blood sampling may still be necessary.

Our finding that some patients with poor clinical grades actually had high flows is interesting. Isolated cases have been reported, in earlier series, of patients with very poor grades having very high flows.

The association between ventricular enlargement and reduction in $\mathrm{CBF}$ seems quite significant. In Bergvall's series (1973), where this was also systematically studied, all cases with enlarged ventricles showed moderately or markedly reduced flow values.

We think, on the basis of this preliminary study, that the Xenon 133 inhalation method will provide useful data in the management of individual patients with SAH. In association with angiography and CT scanning, it should assist the clinical decisions regarding timing of surgery to clip aneurysms, evacuate hematomas, or relieve hydrocephalus.

\section{ACKNOWLEDGEMENT}

We appreciate the financial support of Medical Services Research Foundation (Alberta) which made this study possible.

\section{REFERENCES}

BERGVALL, U., STEINER, L., and FORSTER, D. M. C. (1973). Early pattern of cerebral circulatory disturbances following subarachnoid hemorrhage. Neuroradiol. 5: $24-32$

FERGUSON, C. G., HARPER, A. M., and FITCH, W., et al (1972). Cerebral blood flow measurements after spontaneous subarachnoid hemorrhage. Europ. Neurol. 8: 15-22.

GRUBB, R. L., RAICHLE, M. E., and EICHLING, J. O. et al (1977). Effect of subarachnoid hemorrhage on cerebral blood volume, blood flow and oxygen utilization in humans. J. Neurosurg. 46: 446-453.
HEILBRUN, M. P. and OLESEN, J. (1972). Regional cerebral blood flow studies in subarachnoid hemorrhage. Europ. Neurol. 8: 17.

JAMES, I. M. (1968). Changes in cerebral blood flow and in systemic arterial pressure following spontaneous subarachnoid hemorrhage. Clin. Sci. 35: 11-22.

KAGSTROM, E., GREITZ, T. and HANSON, J. et al. (1966). Changes in cerebral blood flow after subarachnoid hemorrhage. Proc. IIIrd Intl. Congress of Neurol. Surgery, Amsterdam 1966. Excerpta Medica ICS No. 110 pp. 629-633.

OBRIST, W. D., THOMPSON, H. K. and WANG, H. S., et al (1975). Regional cerebral blood flow estimated by 133 Xenon inhalation. Stroke 6: 245-255.

PITTS, L. H., MACPHERSON, P. and WYPER, D. J. et al (1977). Cerebral blood flow, angiographic cerebral vasospasm and subarachnoid hemorrhage. Acta Neurol. Scand. Suppl. 64, 56: 334-335.

SYMON, L., ACKERMAN, R. and BULL, J. $W$. D. et al (1972). The use of the Xenon clearance method in subarachnoid hemorrhage. Post-operative studies with clinical and angiographic correlation. Europ. Neurol. 8:8-14.

WEIR, B., GRACE, M. and HANSEN, J. et al (1978). Time course of vasospasm in man. J. Neurosurg. 48: In press.

ZINGESSER, L. H., SCHECHTER, M. M., and DEXTER, J. et al (1968). On the significance of spasm associated with rupture of a cerebral aneurysm. The relation between spasm as noted angiographically and regional blood flow determinations. Arch. Neurol. 18:520-528. 